\title{
Promoting role of Electronic Commerce on Economic Growth ${ }^{1}$
}

\author{
LIU Weiyue \\ School of Economics and Management \\ Tianjin Chengjian University, Tianjin 300384
}

\begin{abstract}
In recent years, China becomes an important force and focus in the international ecommerce market due to its strong development momentum in the field of electronic commerce. E-commerce has changed the development way of the national economy and people's life style. With this change, the social efficiency are improved greatly. With the expansion of information access, increase to information quantity and improvement of the information processing ability, e-commerce impacts heavily on macro and micro economic environment, reduces the uncertainty of economic activity, ensures the timely application of information, reduces the cost of access to information, improves the efficiency of economic activity, and finally makes higher efficiency of the allocation mechanism for the market resource.
\end{abstract}

Key words: e-commerce; social efficiency; economic growth; allocation mechanism

Through the internet open network environment and based on browser/server applications, both of buyers and sellers are able to conduct business activities without a face-to-face communication. Sellers' cash collection and consumers' payment are processed in a network. A various business activities by consumers (users) and sellers (merchants) through the network, such trading activities, financial activities and related comprehensive service activities ect., form a kind of new commercial operation mode. With broadband internet technology and the rapid popularization of mobile internet technology in recent years, e-commerce market of the developed countries and regions maintained a rapid growth trend. Such countries as the United States, China and the European Union are the main force of e-commerce growth. Very strong development momentum of China in the field of electronic commerce in recent years makes China an important force in the international e-commerce market and focus.

The prevalence rate of network technology and network application in our country is increasing day by day. Internet users in China in 2014 reached over 800 million people, and mobile internet users had more than 300 million people. China became the most active country in the field of global electronic commerce. Electronic commerce is characterized by the advantages of its low cost, high efficiency, high reliability and high integrity, and is favored by consumers, enterprises and businesses. Small and medium-sized enterprises not only take the electronic commerce as a way to find business opportunities, but also put it as a way to win the market. Therefore, China's e-commerce develops by leaps and bounds.

Since 2005, China's e-commerce industry has been developing by high-speed, and expanding rapidly. A varies of enterprises in the field of electronic business information, trade and technology service have gradually penetrated into all walks of life and various fields. In this process, the electronic commerce gradually becomes important force for the transformation of the mode of production development and optimization of industrial structure, in order to

\footnotetext{
${ }^{1}$ Sponsored by Tianjin Science and Technology Commission at project (code:16JCTPJC53400)
} 
effectively improve the operation efficiency and operating performance from all walks of life. In 2016, China's e-commerce market turnover reached RMB 20.2 trillion yuan (about US\$ 2.92 trillion) , up 23.6\% from a year earlier[1] and online retail transactions reached RMB 5.16 trillion yuan (about US\$ 0.75 trillion), up 26.2\% from a year earlier[2]. The growth of shopping market scale by mobile is as high as $200 \%$. Only on November 11 in 2016 (a special shopping day called double eleventh, the eleventh day of the eleventh month in the year), Taobao's turnover is over RMB 120.7billion yuan (near US\$ 20 billion). Taobao is the most famous e-commerce platfrom in China. The position and role of e-commerce in China market trading activities are more and more important. This fully shows that e-commerce has changed the development way of the national economy and people's way of life. With the change of the way, the rhythm of the life and production has been speeding up and as a result, the social efficiency are improved greatly.

The analysis of Adam Smith, a classical economist, on the market price mechanism (the invisible hand) and its role is based on the premise of the complete information market. Chunliang Yang [3] is pointed out that in complete information market, each participant understands all the information he needs and is able to make optimal decisions to buying in or selling out. In real life, however, there is no such complete information market. In a market environment of incomplete information, the amount of information resource will directly affect the participants in the position in the market competition, and also directly affect the efficiency of business activities and the condition of economic resource configuration optimization. Information can be used to deal with the uncertainty in economic activity and can provide production enterprises with the added value. Grasping the information can save resources, improve efficiency, and make the information changed as a resource with social value. With the expansion of information access, increase to information quantity and improvement of the information processing ability, e-commerce impacts heavily on macro and micro economic environment and function, reduces the uncertainty of economic activity, ensures the timely application of information, reduces the cost of access to information, improves the efficiency of economic activity, and finally makes higher efficiency of the allocation mechanism for the market resource.

Song Ze [4] pointed out that the electronic commerce is in a new trend of the blowout development. E-commerce is producing subversive revolution to high labor-intensive traditional service industry thought to be a low technology content. So, the electronic commerce makes the contradiction between the virtual economy and real economy and between online shopping and logistics distribution rapidly intensifying. After the click of a mouse, information leakage, network fraud, lack of integrity and delivery delay are often encountered. On the one hand, the rapid development of information technology and ecommerce improves the transaction efficiency, and on the other hand, it also promotes the formation of perfect competition market.

Wang Yang [5] pointed out that in the past few years, China e-commerce has not only $10 \%$ of the social retail penetration, higher than the developed countries such as America and Japan, but also greatly changed the consumption habits, and promoted the industry chain efficiency revolution. With the online shopping population increased with high speed, e-commerce economy also entered the new normal stage. The development of e-commerce in China is inevitable and results from the multiple factors of internet technology, logistics environment and consumption habits.

Xiao Hongjing etc. [6] noticed the penetration of e-commerce to the traditional industry and constructed a dynamic model of e-commerce promoting the industrial upgrading. The authors 
analyzed the intrinsic motivation factors of e-commerce promoting industrial upgrading, which are technological progress and innovation, and the change of social structure of supply and demand. The paper explained the principle of e-commerce promoting the upgrading of traditional industries.

Cheng Bing [7] in his paper summarized that in the economic globalization, the electronic commerce had become the focus of the society and brought a fundamental revolution to the traditional business activities. On the one hand, the electronic commerce reduces business costs and on the other hand, it improves the efficiency of enterprises, promoting the rapid development of economy. Through an evaluation system established in the paper, impact of ecommerce on economic development was analyzed.

Wang Zhenjiang [8] investigated the function of electronic commerce in resources allocation. As the most typical representative of the economic activity in the information age, electronic commerce is an important driving force of global economic integration. The electronic commerce promotes efficiency of national resources allocation, optimizes the economic structure, and improves national competitiveness. To accelerate the development of ecommerce can not only expand the size of the market but also can adjust the position of China in the global industry.

Pei Ziying [9] considered that as a new trade mode in the information globalization and in a tide of economic globalization, electronic commerce improved the social economic efficiency and increased social total demand with its strong competitive advantage and vitality. By using the theory of economics and a large amount of data, the paper shows the tremendous influence of the electronic commerce upon the macro economy. The paper concluded that the electronic commerce plays sustained and healthy role on China economic development.

Chen Xiaofei [10] analyzed the trend of electronic commerce in China from the perspective of long-term development. He pointed out that China's e-commerce infrastructure is continuously being strengthened and supporting environment is improved. Enterprises' application in ecommerce get further deepened, and so is individual participation in e-commerce. Because ecommerce consumer group in our country grows larger and larger, the electronic commerce in our country will definitely march toward the development path which is characterized by personality. The development of the internet itself complies with the mode of personalized development. Electronic commerce running in the platform will undoubtedly follow up such a mode. In order to meet the needs of each individual better, and with the rising of the people's standard of living, individual personal customized service will no doubt be a development trend of the future.

Zhang Hai-ou [11] and Yi Zhenhua [12] noticed the impact of electronic commerce on the tour industry, analyzed the operation mechanism of the tour e-commerce, and pointed out that visiting rates and click rates are very important for the tour website, and they affect the attention of travelers and the investment of advertisers. Tour online direct sales mode replaces the traditional marketing mode and agency mode. The development of the tour e-commerce will focus on direct communication with customers. Tour electronic commerce can not only guarantee the realization of the specific target, but also save the required resources, so as to promote the rationality of social resource allocation.

$\mathrm{Xu}$ Weitao [13] analyzed the basis of China's e-commerce popularization, and pointed out that with the rapid development of China's economy, e-commerce has become the shopping mode 
favored by people. It is due to convenient and quick shopping way and the low-price advantages that e-commerce rapidly develops in China. Ten years ago, portal era for China's ecommerce happened, and 10 years later, the marvelous change finally occurs.

On 2013 online carnival due to large online sells, e-commerce proved that it strongly boosted economic growth. Studying on the source of the e-commerce in China, it is helpful to understand that e-commerce will become a new engine to lead China's economy.

\section{The e-commerce changes business mode}

Under the traditional business mode, it is difficult to achieve efficient allocation of social resources, and its reason is shown in three aspects.

1. The traditional business transaction is controlled by the sellers. Under this mode, the customers have no choice on shopping time and deal way. The stores or the sellers rule the operating time, the trading way and trading site. For shopping, the customers have to obey these provisions. Beyond the rules, the customers' needs to shopping are not achieved. Deal between both sides of the merchants and customers cannot be reached. For example, if merchants rule that to sell clothing must not try it on, the customer, in order to get the clothing, will reluctantly accept the provisions. Furthermore, some merchants specify that a credit card is subject to charge fee for the trading, and the customers have made a special trip to find an ATM to withdraw cash in order to reduce the fee. And so is for operation hours. Restrictions on operation hours will inhibit the customers in shopping desire, the sellers also missed the chance to deal the buying and selling, and the customers lost business opportunities. The customers will encounter difficulty and be subject to loss. In rainy days, a consumer who needs rain gear arrives a shop and finds that the store has been closed; a customer to need a drug is unable to find pharmacy nearby. How anxious mood customer's failing to meet their needs, as you can imagine it. The consumer's shopping needs are not met, which is not because of a short of supply but because the consumer has no right to choose the way to get goods. This is why the traditional business mode is inadaptable to market transaction.

2. Under the traditional business mode, a blind area exists for the commodity information. People has a lack of understanding to commodity information in shopping mall, and they make no comparison. It is difficult to judge or find their suitable goods. When people want to shopping, their choice of shopping place is imaginary. The consumers do not know and are not clear that there what kind of goods in which shopping malls, or which business circle, how the quantity of goods is, how goods design is, how their specifications are, how their properties and functions are, and whether or not suitable to themselves. They can only by subjective make choice to the shopping mall. Which store is easy to arrive (or by bus, by driving or by walk), whether or not is the shopping environment comfortable on the shopping day (how many customers, indoor air quality, customer rest area), and whether or not will store staff be able to provide satisfactory service (how many service personnel, their mood and attitude), etc. Before the customers go to the mall, the situation are unpredictable. The customer shopping often fails, thus increasing the cost of shopping. They have to give up some demand, and that is, inadequate information results in that the customers cannot meet the demand.

3. Under the traditional business mode, the trading way cannot provide the consumer with convenient and pleasant service. Some consumers must wait or queue up for shopping and payment. In their consumption, some urban residents need face-to-face payment by the supply department of water, electricity, fueling gas and central heating. The supply department will allocate persons to visit the residents at home in order to receive their expense. That is very inconvenient. Payment way becomes a big burden for consumers and takes extra time. Many consumers depressed the way, not because of 
the lack of payment ability, but because of time-consuming for the payment. Under the traditional business mode, the wasting additional time occupies a certain proportion in transaction costs.

\section{Improvement of electronic commerce on social efficiency}

Economic research and description to the problem of efficiency tend to associate with fairness. The efficiency and fairness are two major goals of society to expect. They are corresponding to each other, unified to each other and complementary to each other. The efficiency influences on social economic growth, being fair or not relates to social harmony and stability. Efficiency is essentially the problem how to achieve the effective allocation of social resources; Fairness is essentially the problem how to deal with all kinds of relations in social economy. Obviously, the efficiency to lose fairness and the fairness without speaking the efficiency are meaningless. And in our time which is characterized by high speed development of social economy, it is very difficult for the traditional business mode to realize the unity of efficiency and fairness. Because of its openness which is characterized by transmitting information through the network, e-commerce makes the market transaction and competition fairer and more reasonable. Industry boundaries become more blurred, and all kinds of enterprises are faced with the same competitive. Under the impact of the network, enterprises will be difficult to survival and development in the network era if they lack of innovation consciousness and cannot improve products and services in time.

The internet is used with low cost and wide coverage. E-commerce has an advantage of full function and flexible use. The e-commerce is widely applied in the social business, and promotes the improvement and increase of the social efficiency.

1. The forming of a virtual market brings a significant change in the trading way and the trading environment. Online ordering, online promotions, online inquiry, online negotiation and online trading provide the trading activities with online virtual information exchange. This new market space breaks through the prerequisite of the traditional market which must exist in a certain region. Global and unified big market is formed by taking information network as the link, in order to promote the formation of the globalization of world economy and at the same time to be benefit to the optimal allocation of social resources.

2. The appearance of a virtual company caused a major change of the operators in the trading activities. Modern communication technology enables many companies to joint with each other to establish huge information network. In this way, through the combination of core technology of a single company in its respective fields, the market function is achieved in order to provide the market and the society with goods and services more effectively. The virtual company does not have mandatory power to each of the associated companies in the capital relationship, but due to the role of the network information functions, it has changed some substantively. Merchants and buyers from all walks of life can carry out transactions through e-commerce, and such transactions will be more convenient, fast, safe and fair. The the working efficiency is greatly increased, and its effectiveness greatly improved.

3. Big changes occur for trading operation in the way of management. Based on computer network and information technology, the e-commerce system provides the society trading activities with open market environment in which an information is complete, so as to achieve the efficient allocation of social resources and production elements and to make the market mechanism play a full role. Trading under the e-commerce system has changed the traditional trading process and its management mode, breaks through 
the operation mode of traditional trading activity which emphases only on one-way logistics, and start with a new trading process. The process will integrate information flow, trading flow, capital flow and logistics as a whole.

4. There is also big change with organization structure for trading intermediary organization. Producers and users and consumers can directly contact and communicate among them through the network, which makes it possible to timely supply and to realize zero inventory. And so, goods flow smoothly. Information network is used as communication platform or media, straightens out the principal-agent relationship resulting from the information asymmetry and eliminates the uncertainty caused by the reasons. The trading intermediary organization loses the possibility of survival.

\section{The technical and economic analysis of influence of electronic commerce upon the social efficiency}

Merchants and buyers conduct trading activity under the environment of e-commerce to save their own time and to produce the extra economic benefits. In modern society, the demand of people is full of personalization. In order to win bigger profit, the enterprise must operate on large-scale production. The personalized demand and the large-scale production make the enterprise narrow its profit space, so as to increase the difficulty of the enterprise winning profit. In order to effectively solve the conflict of the demand and production, the enterprise only make full use of e-commerce. By developing the e-commerce platform and customer selfservice way, the electronic commerce effectively reduces the cost in order to meet huge personalized demands and at the same time to form the large-scale, personalized demand through search engines and word-of-mouth to spread.

3.1 At the macro level, the electronic commerce provides both parties of supply and demand at the market with extensive contacts and exchanges for the worldwide and draws great attention of the countries. Around the world, the electronic commerce is actively used, to vigorously develop the regional economy. In order to implement task objectives of the 12th five-year planning outline of our country for the national economic and social development about the development of e-commerce, the local governments across the country are in full depth in the creation of national e-commerce demonstration city. The governments increased the investment in e-commerce. They have been striving to complete the link up about the development of electronic commerce and modern service industry and strategic emerging industries, and gives strong support in the area of infrastructure and public service platform for electronic commerce applications, supporting system construction, and so on. Governments' support to e-commerce will have a far-reaching influence on national economy industries. E-commerce will also have a huge role to the development of national economy.

E-commerce shows its roles in the following aspects:

1. The electronic commerce and its development enhance the economic function of information and promote the development of the information industry. In turn, the development of information industry also promotes the development of electronic commerce. Information technology represented by e-commerce develops in an exponential growth trends, and becomes accelerator and important force of a national economic growth. As a public product, information usually is not exclusive. Once the information becomes a realistic productivity, it can quickly diffuse and disseminate. The diffusion and dissemination promote rapid improvement in productivity through chain reaction with no cost, so as to promote the rapid development of the whole national economy. In addition, as an implicit means of adjusting resources optimization 
configuration, the information has the same adjustment role with the market price mechanism named as the 'invisible hand'. When the market price mechanism fails, the information plays an important role in filling the gap, so as to make the operation of the economy back into balance.

2. The electronic commerce leads to the change of the economic operation mode to the market. In facing e-commerce environment, enterprises must adjust or change the way of their operation and management. The traditional market structure has changed. The enterprises and their management thinking change along with the change. Production way of 'Supply pushing' is no longer adapt to the development of the market, and will be replaced by 'demand pulling' way. Traditional business activities are carried out under the condition of the face-to-face contact. Business travel for marketing, sales and aftersales is subject to a big spending. And so transaction costs are high. Since it was born and run, e-commerce completely changed the face to face way to conduct business. It makes all kinds of business activities carry out in computer network platform, greatly reduces the transaction cost and completely changes the operation mode of the market economy.

3. The electronic commerce promotes function transformation and the change of management philosophy for government sectors. In addition to both trade parties, many sectors of government participate in the electronic commerce, often involving industrial and commercial administration, customs, insurance, taxation and banking etc. In order to develop electronic commerce healthy and orderly, the government is doing strong and comprehensive coordination by adjusting means of the law and policy. The development of electronic commerce makes many works of the government in supervision and management from passive adaptation to active coordination, also effectively promote the transformation of government departments and their staff management. Government focusing on great importance to the development of ecommerce will certainly brings infinite vitality and broad prospects to regional economic development .

4. E-commerce has become an innovative means of collecting and monitoring regional tax. Network tax-declaring system can not only facilitates the taxpayers in paying a tax, but also effectively prevents the tax evasion. At the same time, e-commerce transactions is characterized by traceability, the data are real and reliable, and the goods in transaction and their prices can be used as the tax basis. E-commerce trading platform can also realize real-time declaring and paying tax by connecting with the tax system.

5. Adjustment of the electronic commerce to the world economic structure. For developed countries, their economic structure is toward the higher level development and their economic development speed is very fast, by giving priority to with high-tech technology and information industry development. Electronic commerce is in this period due to the rapid development of information industry. At the same time it also leads and promotes the development of information industry, so as to speed up the pace of the world economic structure adjustment.

3.2 On the micro level, the electronic commerce has huge impact on manufacturers and consumers. Enterprises use e-commerce to innovate their business mode. Thereby it directly saves expenses on communication, negotiation, business, marketing and others, increases business performance and produces the actual economic value. Personal use of e-commerce may transform peoples' ideology and attitude towards life, can make their work and life easier and on the other hand, e-commerce speeds up rhythm of the work and life. E-commerce shows a great push to the development of social economy, which is reflected in the following aspects: 
1. Changing the management and operation of the enterprise. In the age of Internet, the enterprises will face a new change in the needs and purchasing behaviors of the customer, must redesign own work process based on the final customer and change the traditional management works. In order to win the market or to expand market share, the enterprises need to make a rapid response to the market. E-commerce provides the enterprises with the tools and measures to achieve the goal, which is convenient to obtain the market information and to get feedback from the market. Enterprises can get more quickly information about procurement, marketing, services, and even hiring, financing through e-commerce channels, and more accurately grasp the opportunity. At the same time, it can make enterprise reduce operating error, and save operating cost and time. In order to get more discounts on purchasing, the enterprises can close relationships with their suppliers under the electronic commerce environment. And the suppliers are able to participate in the production process of this enterprise, so as to timely provide the enterprises with the right amount of raw materials, equipment, capital and manpower. E-commerce efficiently compresses the enterprise inventory, lean logistics and reduce the backlog of funds.

2. Changing the way of personal thinking, work and life. People use the Internet to get a lot of information and business opportunities. They can work, do business negotiations and purchase goods by staying at their home. The Internet makes it convenient to process transaction for travel deals, such as buying air tickets, train tickets or bus tickets, car rental and hotel reservation, the conference room reservation etc. Every year, one purchases such services, (shown in Table 1-2). All data of the tables are from reference [14].

Table 1 Online retail market transaction size

\begin{tabular}{|l|l|l|l|l|l|l|}
\hline Years & 2011 & 2012 & 2013 & 2014 & 2015 & 2016 \\
\hline \$,billions & 116.2 & 191.4 & 241.3 & 408.9 & 554.6 & 756.8 \\
\hline
\end{tabular}

Since ALI strategically invested Suning and Jingdong invested Yonghui, purchased shop No. 1 and reached a strategic cooperation with WAL-MART, the Internet retail development had gone to the combination of the new stage. With the Internet online business develops in steady growth, the offline business will become a new growth point of the Internet.

Table 2 The proportion of the online retail market transaction scale in total retail sales of social consumer goods

\begin{tabular}{|l|l|l|l|l|l|l|}
\hline Years & 2011 & 2012 & 2013 & 2014 & 2015 & 2016 \\
\hline Proportion & $4.10 \%$ & $6.30 \%$ & $8 \%$ & $10.60 \%$ & $12.70 \%$ & $15.10 \%$ \\
\hline
\end{tabular}

The reasons are: 1.The proportion of total retail sales of social consumer goods is increased continuously, thus stimulating domestic demand. Online shopping has changed the user's shopping habits, stimulated the user's shopping potential. 2. A series of smaller cities, continue to maintain the scale of online shopping, the e-commerce continuous innovation, such as "Net Red + live", stimulate new purchases desire.

At the Internet platform, consumers are able to make comparison with performance and price of goods or services through full and public information, shorten the transaction time and reduce the transaction cost (shown in Tables 3-5), so as to increase the user's identity and satisfaction of service for the deal. People prefer this way of working and living more and more. All data of the tables are from reference [14]. 
Table 3 Online shopping user scale

\begin{tabular}{|l|l|l|l|l|l|l|}
\hline Years & 2011 & 2012 & 2013 & 2014 & 2015 & 2016 \\
\hline Users,millions & 203 & 247 & 312 & 38 & 460 & 500 \\
\hline
\end{tabular}

The reasons are: Online shopping users grow faster, especially mobile end users beyond the PC end user. Mobile terminal is more in line with user habits.

The rise of the middle class consumer groups, it means that the higher requirements occur in the quality, and there is a contest for the e-commerce in the brand, logistics, services and other aspects.

Table 4 Mobile online shopping transaction size

\begin{tabular}{|l|l|l|l|l|l|l|}
\hline Years & 2011 & 2012 & 2013 & 2014 & 2015 & 2016 \\
\hline \$,billions & 1.68 & 10.01 & 39.58 & 134.57 & 292.52 & 538.26 \\
\hline
\end{tabular}

Tmall, Jingdong, Vip.com and so on enter the mobile field in depth. 2016 second quarter earnings of Ali and Jingdong showed that the Alibaba retail platform for mobile terminal reached 17.514 billion, accounting for $75 \%$ of China retail platform's total revenue; Jingdong orders in the mobile terminal channel accounted for about $79.3 \%$ of the total volume of orders completed, an growth of more than $130 \%$. By combining of 020 and rural e-commerce and cross-border e-commerce, mobile e-commerce will release the consumption potential.

\begin{tabular}{lcccccc}
\multicolumn{7}{c}{ Table 5 Revenue of e-commerce logistics industry } \\
Years & 2011 & 2012 & 2013 & 2014 & 2015 & 2016 \\
\$,billions & 8.38 & 15.29 & 20.88 & 29.64 & 40.13 & 57.39
\end{tabular}

China government encourages and supports the e-commerce development and China's express industry develops rapidly in recent years. The volume of business and revenue growth in recent years and the growth is in a gradual accelerate trend.

3. Making a breakthrough of the limitation of the business activities in time and space. Ecommerce makes trade business process tend to be more flexible, to be real-time and internationalization. Enterprises will increase business opportunities and the individual will be more convenient. Internet thinking will lead to the development of electronic commerce beyond the infinite.

\section{References}

China e-commerce Data center. Database for electronic commerce [EB/OL]. http://www.100ec.cn/detail-6379369.html

China e-commerce Data center. Database for electronic commerce [EB/OL].

http://www.100ec.cn/detail--6383946.html

Chun-liang Yang, the economics of electronic commerce thinking [J]. China's collective economy, 2009 (7) : 73-74

Ze Song, "blowout" development trend of electronic commerce [J], journal of Beijing finance \&trade vocational college, 2013 (6) : 7-9

Wang Yang. E-commerce Economy entering the period of policy profit and innovation[J]. Social Outlook. 2015, (12): 48-50

Xiao Hongjing, Xiao Yan, Zou Wenjian. Study on the Mechanism of E-commerce Promoting Industrial Upgrading[J]. Science Mosaic. 2016,(10): 148-151 
Cheng Bing. The Effect Measurement of e-commerce on the Economic Development[J]. Journal of Commercial Economics. 2016,(19): 79-81.

Wang Zhenjiang. The impact of e-commerce on China's economic development[J]. Marketing Management Review. 2016,(3): 16-17

Pei Ziying. E-commerce and China Macro economy[J]. Journal of Jilin Institute of Chemical Technology. 2015,(7):13

Chen Xiaofei, Analysis on status and trend of China electronic commerce development [J]. Market Modernization. 2014, (9) : 31-32

Zhang Hai-ou Design of research framework for tourism electronic commerce operation mechanism [J]. Seeker, 2013, (8) : 256-258

Zhen-hua Yi, Analysis of development status and countermeasure for China tourism electronic commerce[J]. Entrepreneurs World. 2014, (01): 15-16

Xu Wei tao, Prospects and development of China's electronic commerce[J]. China, 2014, (14):75-76

Zhang Zhouping. Data Monitoring Report of China e-Commerce Market for first half of 2016 [R]. Beijing: China Electronic Commerce Research Center. 2016 